\title{
LUZ, ARTE Y FÍSICA. LA FÍSICA EN LA PINTURA ${ }^{1}$
}

\author{
Christian Wagner López \\ Universidad de Cádiz
}

Esta obra está formada por un CD con 17 presentaciones en PowerPoint y un libro con las explicaciones a sus 2133 diapositivas. Es una nueva forma de enseñar y divulgar la Física que parte de la investigación de los fenómenos físicos reproducidos por los pintores y se presenta como una visita a un museo virtual guiados por un profesor de Física. No es una crítica de arte sino un acercamiento al Arte desde la Física. Es igualmente, un curso divulgativo de Física para el que no se requiere un nivel previo y está especialmente indicado para aquellos que piensan que la Física no es lo suyo.

Otro aspecto novedoso es su programa, trazado por la luz. Parte de la propagación rectilínea de la luz y los reflejos y refracciones que sufren sus rayos para estudiar finalmente los instrumentos ópticos. Es asombroso los aspectos de los cuadros que pone de relieve este estudio a la vez que nos inicia en el método científico con la observación, el planteamiento de hipótesis y la comprobación que muchas veces se realiza mediante maquetas de los cuadros.

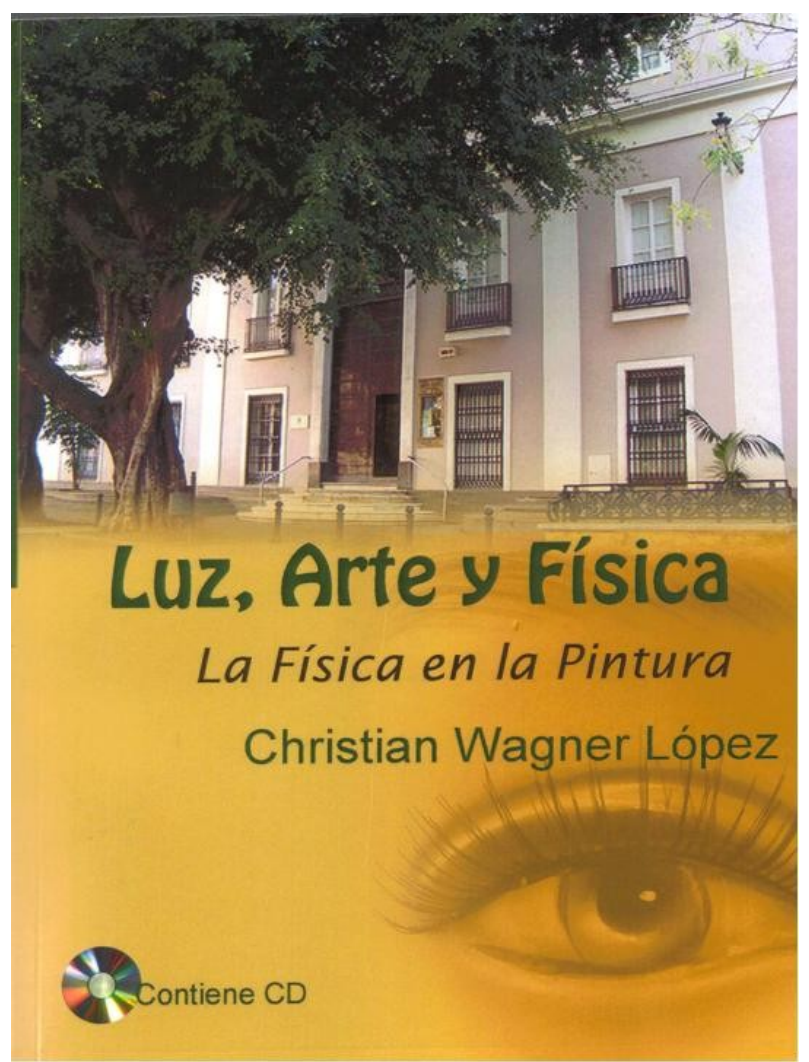

El intento de Galileo de medir la velocidad de la luz, nos introduce en el estudio del movimiento, comparando la forma de expresarlo el artista y de analizarlo el físico. La dinámica nos lleva a estudiar las causas del movimiento de los cuerpos que con la teoría de la gravitación nos lleva a comprender por qué sube el humo y vuelan los aviones, entre otras muchas cosas. El estudio de las máquinas simples, ampliamente reproducidas en los cuadros, lleva a comprender que es la energía, sus fuentes y su relación con el trabajo, concluyendo con el estudio de la primera maravilla tecnológica, la rueda.

La propagación de la energía introduce en el estudio de las ondas y del sonido, así como de los instrumentos musicales. De esta forma se está preparado para estudiar la naturaleza de la luz, el color así como los colores de la naturaleza; el arco iris, el color del cielo y del 
agua, las puestas de sol, el rayo verde,... "La historia de la iluminación" es el colofón al estudio de la energía y "El reto de los reflejos" al estudio de la luz.

Parte de este material ha constituido el curso del Aula de Mayores de la UCA del mismo nombre, pero su enfoque original y su atractivo lo hace idóneo para utilizarlo en la Enseñanza Secundaria y como material complementario en cursos de Física y de Óptica a nivel universitario.

El autor es catedrático de Bachillerato en excedencia y Profesor Titular de Universidad con destino en el Departamento de Física de la Materia Condensad de la Facultad de Ciencias de la Universidad de Cádiz. Aparte de su labor investigadora, ha realizado múltiples trabajos y publicaciones sobre la Física y su enseñanza.

${ }^{1}$ Imprime y distribuye Copistería San Rafael, c/ Benjumeda 34 - 11003 Cádiz. De venta en Librería San Rafael, c/ Benjumeda 37 (Cádiz) y en las copisterías de las Facultades de Filosofía y Ciencias, y en la Politécnica de Algeciras. 